\title{
SUSTENTABILIDADE DA URBANIZAÇÃO EM ÁREAS DE RESTINGA: UMA PROPOSTA DE AVALIAÇÃO PÓS-OCUPAÇÃO
}

\author{
Werther Holzer \\ Professor adjunto (doutor em geografia humana - USP) \\ da Escola de Arquitetura e Urbanismo da Universidade \\ Federal Fluminense. \\ e-mail:werther.holzer@bol.com.br
}

\section{Jorge Crichyno}

Professor adjunto (mestre em ciências ambientais) da Escola de Arquitetura e Urbanismo da Universidade Federal Fluminense.

e-mail: jorgecrichyno@hotmail.com.br

Alice Cabanelas Pires

Bolsista Pibic/UFF/CNPq.

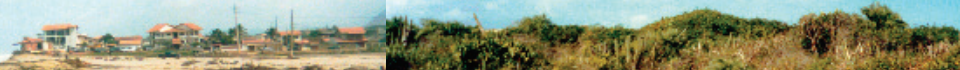




\section{RESUMO}

O objetivo deste trabalho é, segundo um contexto de avaliação pós-ocupação, propor a implementação de ações relativas ao projeto urbano e paisagístico que viabilizem uma compatibilização entre unidades de conservaçãa de vegetação de restinga e as áreas urbanizadas de seu entorno, visando à sua utilização enquanto pólo de ecoturismo e de pesquisa científica.

A proposta deste texto é apresentar uma avaliação preliminar do impacto causado pelo parcelamento e urbanização sobre a vegetação de restinga, utilizando-se da própria vegetação como marcador deste impacto. Para isso foi selecionada uma área do estado do Rio de Janeiro - a Restinga de Maricá, originalmente ocupada por vegetação de restinga que se encontra hoje em estágios bastante diversificados de urbanização e, conseqüentemente, de degradação.

Essa área tem a particularidade de conter, e de ser limítrofe, à unidade de conservação denominada Área de Proteção Ambiental Estadual da Restinga de Maricá, o que permite a utilização das áreas ainda preservadas como marcadores para a análise das áreas urbanizadas.

A partir dessa avaliação se pretende aferir o potencial paisagístico dos conjuntos vegetacionais e as medidas de conservação, recuperação e planejamento urbanístico e ambiental que permitam a exploração auto-sustentável do ecoturismo e das atividades comerciais, de serviço e residenciais nas áreas em questão, ou seja, de um desenho urbanístico e paisagístico o qual tenha a maior fidelidade possível com a paisagem natural da restinga, propiciando um equilíbrio entre as espécies vegetais a serem utilizadas, e que possa servir de suporte à fauna nativa.

Palavras-chave: Sustentabilidade, urbanização, conservação, recuperação.

\section{ABSTRACT}

The objective of this work is, in one context of APO, propose actions in urban and landscape planning, checking the potential of the species that composes the vegetation of this area. Seeking to guide a possible landscape and environmental reconstitution, and the compatibleness between conservation areas and urban areas that will be used to ecotourism and scientific research.

This work tries to follow a preliminary evaluation of the impact occasioned upon the shoal vegetation for the urbanization, where the vegetation is the impact marker. We are selected one area of the State of Rio de Janeiro - the shoal of Maricá, originally occupied for shoal vegetation, and today's in different stages of urbanization and degradation.

This area has the particularity to contain, and confined, a Conservation Unity: the Área de Proteção Ambiental Estadual da Restinga de Maricá, which afforded a comparison between the conservation unity and the urbanized areas.

These evaluations intend compare the landscape potential of the vegetacional groups. Propose the conservation, recuperation and the urban and environmental planning that permit an exploitation of ecotourism, trade and residential activities. We hopes to contribute for a consolidation of landscape planning that considers the ecological, scientific and tourist potential of that area in subject.

Key words: Sustainability, urbanization, conservation, restoration, restinga forest. 


\section{SUSTENTABILIDADE DA URBANIZAÇÃO EM ÁREAS DE RESTINGA: UMA PROPOSTA DE AVALIAÇÃO PÓS-OCUPAÇÃO}

\section{Introdução}

Este trabalho recorre às pesquisas que foram realizadas no ano de 1993, visando ao estudo das comunidades vegetais da APA de Maricá para sua posterior utilização em projetos paisagísticos em áreas litorâneas (CRICHYNO, 1996); na compilação de dados institucionais disponíveis sobre a APA de Maricá (HOLZER, 1999); no estudo dos conjuntos vegetacionais que compõem a APA de Maricá (CRICHYNO e HOLZER, 2000); e a pesquisa intitulada "Avaliação Pós-Ocupação da Urbanização de Restingas: Impactos Ambientais de seu Parcelamento" (HOLZER e CRICHYNO, 2002).

Propostas de avaliação pós-ocupação se referem, geralmente, a edificações ou conjuntos de edificações, e são realizadas a partir de uma enquete que gera dados analisados quantitativamente. Nossa proposta é fazer uma avaliação do impacto causado pelo parcelamento e urbanização de modo qualitativo, ou seja, comparando, a partir de dados cartográficos, de fotografias, excursões a campo e entrevistas, as diversas possibilidades de implantação de um assentamento urbano. Para isso elegemos um marcador: a vegetação nativa, que nos casos analisados é de restinga. Selecionamos diversas áreas em que ocorre este tipo de vegetação no estado do Rio de Janeiro, todas limítrofes a áreas de proteção ambiental. Este artigo trata, especificamente, da Restinga de Maricá, situada no município do mesmo nome, no estado do Rio de Janeiro. Esse sítio se encontra totalmente parcelado com taxas de ocupação bastante diversificadas, podendo ir de 10\% a 100\% da quadra. A área de Proteção Ambiental de Maricá, que até hoje não possui plano diretor aprovado, foi mantida como área non aedicandi pela prefeitura municipal.

\section{Processo de Urbanização e Impactos Ambientais Sobre a Vegetação}

Cerca de $5.000 \mathrm{~km}$ do litoral brasileiro é ocupado por ecossistemas de restinga e dunas de areia. Esses sistemas, localizados na interface entre os ambientes 
marinho e continental, possuem uma fragilidade intrínseca. Ao se constituírem como ambientes de transição oceano/continente, as zonas costeiras são constantemente afetadas por processos naturais de deposição marinha (ação eólica e marinha) e de drenagem fluvial, desenvolvendo aspectos sedimentares simultâneos em termos da predominância de um ou de outro fator ecológico. As zonas costeiras do estado do Rio de Janeiro constituem significativos exemplos de seqüências sedimentares regressivas e transgressivas associadas às variações do nível do mar durante o quaternário e ao aporte sedimentar do litoral, principalmente de origem fluvial. Isto se relaciona à ocorrência da componente vegetacional. As feições morfológicas do ecossistema de restinga ao longo do litoral fluminense são representadas por cristas de praias (beach ridges) e sistemas de restingas (barrier systems). (Figura 1 - Perfil da Restinga). As restingas constituem um dos ambientes naturais mais visados e explorados pelo turismo e atividades de lazer, com conseqüente ocupação antrópica por meio da urbanização. Como ecossistema litorâneo, a restinga se constituiu um dos primeiros ambientes a sofrer intervenção antrópica após a chegada dos europeus (DEAN, 1996). Na verdade, a utilização das restingas remonta à pré-história brasileira, como testemunham os vestígios arqueológicos encontrados em todo o litoral brasileiro, inclusive nas áreas de estudo propostas neste trabalho, e os relatos dos primeiros viajantes a tocarem nosso litoral (STADEN, LÉRY, ANCHIETA, p. ex.).

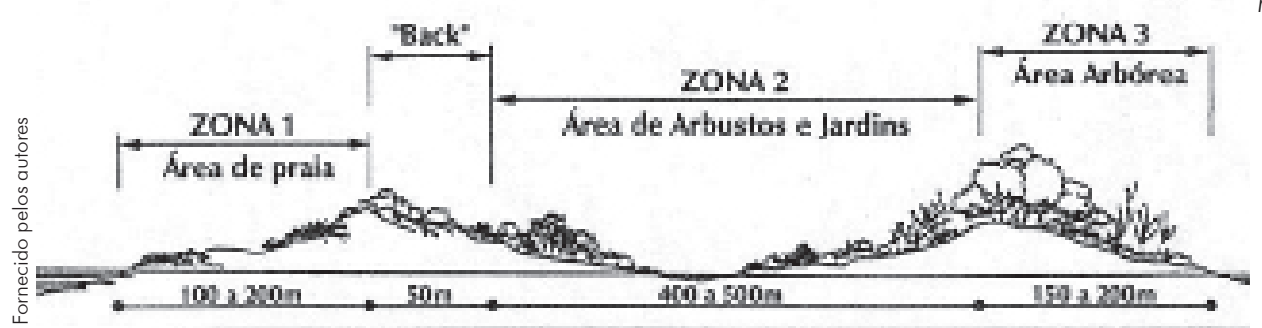

Figura 1: Perfil da restinga

A ocupação do litoral pelos europeus iniciou um ciclo de exploração mais intensivo dos recursos naturais da faixa litorânea, levando ao corte de madeira para diversos fins, e a utilização do solo para fins agrícolas, e, no caso das restingas, onde o solo é "pobre", para fins de pecuária.

Mais recentemente, essa faixa litorânea passa por um processo de degradação mais intensa devido à exploração de areia e turfa, ao uso de veículos, à retirada indiscriminada de espécies vegetais, à sua utilização como depósito de lixo, e, de modo definitivo, por seu parcelamento e ocupação por loteamento. Nesse sentido, a crescente atividade humana tem levado a uma desestabilização progressiva de seus componentes biológicos e paisagístico-ambientais, com a conseqüente degradação decorrente dos impactos da expansão urbana, voltada, muitas vezes, para o caráter especulativo. 
A necessidade de estudos voltados para um processo de gestão e planejamento ambiental que considere os fatores ecológicos, paisagísticos e turísticos, conciliados com os princípios de conservação, possivelmente poderão minimizar os efeitos da degradação socioambiental do ecossistema de restingas.

As restingas de hoje já não possuem a exuberância descrita pelos naturalistas e cronistas que aqui estiveram entre os séculos 16 e 19 (Soares de Souza, Neuwied, Darwin, p. ex.). Atualmente a vegetação de restinga está reduzida, e confinada, a pequenas manchas remanescentes - que serão utilizadas neste trabalho como marcador para a avaliação pós-ocupação das áreas urbanizadas - e a situação de sua fauna se configura ainda mais crítica. Entretanto, em diversos locais, essas manchas de vegetação se constituem em ambientes bastante diversificados, que merecem ser preservados e recuperados, mas que estão altamente ameaçados pela expansão urbana, principalmente a voltada para a especulação imobiliária.

Durante o processo de urbanização ocorre, necessariamente, a fragmentação do ecossistema com a formação de manchas verdes de diferentes formas, tamanhos e graus de isolamento. Estudos científicos têm demonstrado (ANDRADE, 1967) que há uma correlação comparativa referente ao aumento do tamanho das ilhas de vegetação, relacionado a uma maior variabilidade de ambientes e quantidade de recursos em seu interior, o que diminui a probabilidade de extinção das espécies.

Ainda em relação à "Teoria de llhas", verifica-se que o isolamento da ilha (ou mancha verde) tem determinado a taxa de colonização da mesma, ou seja, ilhas de vegetação mais próximas da fonte de espécies são mais facilmente colonizadas por novas espécies, aumentando sua diversidade, ou são mais facilmente recolonizadas pelas espécies que sofreram eventual extinção no local da ilha.

Com relação à forma que a mancha verde apresenta, segundo Goldstein (1981), foi verificado que é mais importante no caso das manchas pequenas (no qual a relação perímetro/área é maior) - quanto maior o perímetro em relação à área, maior também será o contato da mancha com o ambiente urbano e poucas espécies sobrevivem nestas condições.

Uma menor relação perímetro/área implica uma grande extensão interna da mancha verde (ilha) com condições mais naturais, o que permite a manutenção da diversidade de espécies, original da mancha. A forma circular é a que minimiza esta relação perímetro/área e deve ser objeto de nossos estudos.

Nesse sentido, Goldstein (1981) verificou que a tendência histórica da urbanização de dividir os parcelamentos em lotes retangulares faz com que as manchas de vegetação, eventualmente preservadas, sejam pequenas e 
sujeitas à intervenção humana. Os mesmos autores propõem outros desenhos formais, como, por exemplo, formas hexagonais, nos quais os lotes seriam fatias triangulares do hexágono.

Outros estudos (BLOUIN e CONNOR, 1985), no entanto, discutem a possibilidade desse sistema apresentar falhas, argumentando que ele não permitiria a manutenção do gradiente ambiental perpendicular à praia, além de não considerar comportamentos culturais como o de cercar ou murar os lotes, o que causa fragmentação da mancha verde e uma grande intervenção no centro da mesma, local de encontro das cercas.

Neste trabalho se pretende discutir esses parâmetros de parcelamento, considerando a otimização da preservação da restinga em consonância com as aspirações sociais, culturais e ambientais de seus diversos usuários.

\section{Análise Urbanística da APA de Maricá}

A área em questão é constituída por extenso cordão litorâneo, com cerca de $20 \mathrm{~km}$ de extensão, caracterizado geologicamente e, em termos de vegetação, como uma formação de restinga. Essa caracterização indica um sistema geológico precário, que, se não estivesse associado à vegetação, fixando seu solo arenoso, poderia ser facilmente destruído pela violência do mar. Esse o motivo que recomenda um estudo aprofundado e judicioso de qualquer intervenção humana, em especial a urbanização.

A Área de Proteção Ambiental de Maricá, criada em 1984, é a mais antiga APA sob administração estadual, sendo gerenciada pela FEEMA, órgão de fiscalização ambiental do estado. A área protegida abrange 496 hectares de vegetação de restinga, em uma estreita faixa que se estende no sentido leste-oeste, espremendo-se entre o Oceano Atlântico e a Laguna de Maricá, no sentido sul-norte (SEMAM/IEF, 1994).

A colonização da área é antiga, datando do século 16, mas as condições da costa, impróprias para se aportar, e do solo, arenoso na restinga, impeliram a ocupação para o interior, na orla entre as lagunas e a serra, onde se implantou a Vila de Maricá, circundada por prósperos engenhos de açúcar e de aguardente. No entanto, a pesca era sua atividade mais importante, sendo a colônia do Zacarias, situada na APA, responsável, em 1940, por 1/3 da produção pesqueira do estado (LAMEGO, 1974).

A expansão urbana é recente, mas a quase totalidade da restinga já estava loteada na década de 80, quando as atividades, tradicionais do município, inclusive a pesca, iá haviam entrado em decadência. Os anos 90 marcam uma expansão, e especulação imobiliária intensiva, quando o município mais que dobrou sua população de residentes. 


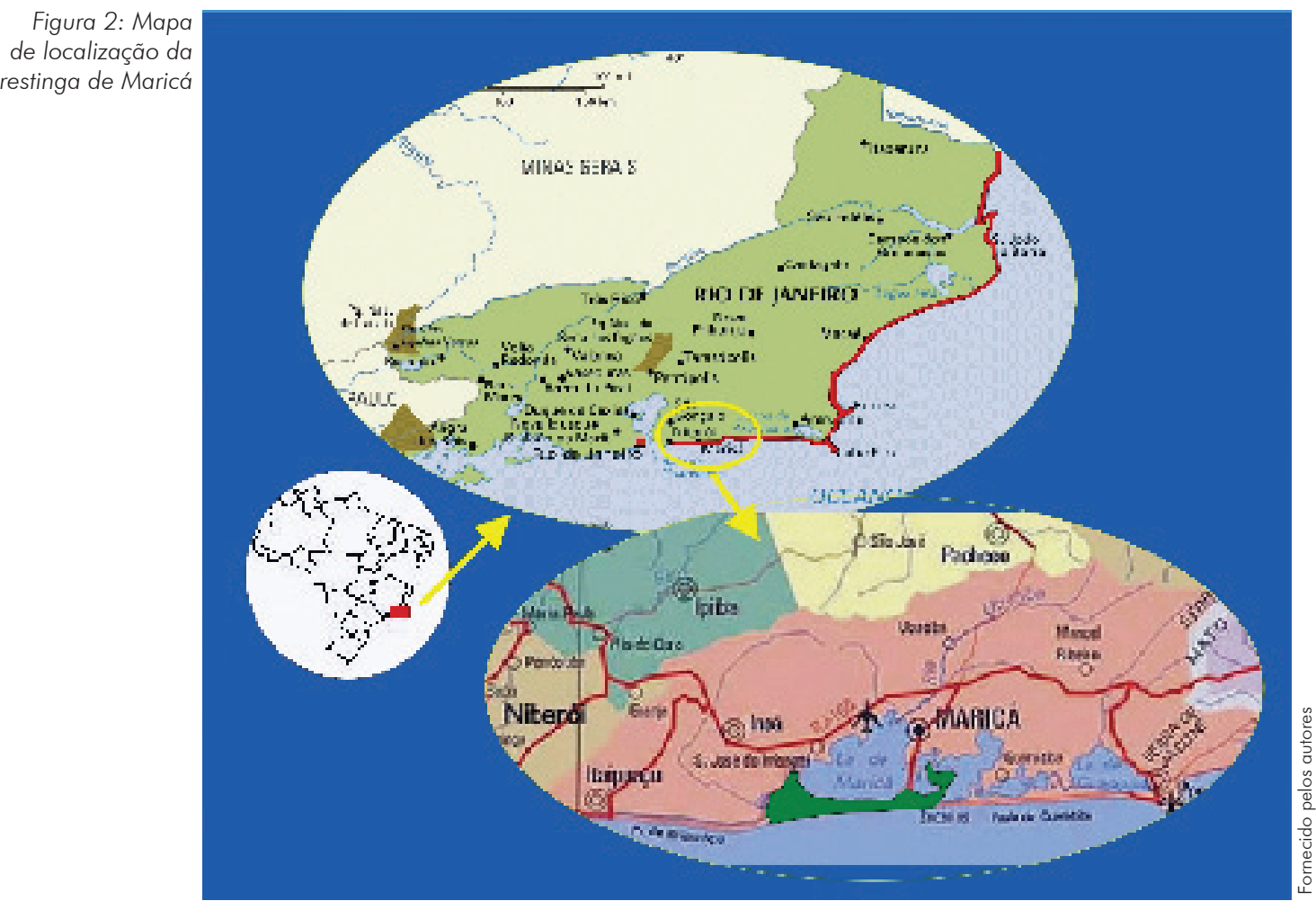

Atualmente a APA de Maricá é a única área de restinga relativamente preservada no litoral, estendida de Niterói até Saquarema (cerca de 150 km de costa), mas é um local pouco freqüentado por moradores e turistas. A área se tornou um gigantesco local de despejo. Junte-se a isso o roubo endêmico de areia, que destrói as dunas e compromete a própria estabilidade da restinga, e a retirada indiscriminada de espécies vegetais vendidas clandestinamente, além das queimadas promovidas por motivos fúteis.

O plano diretor de Maricá, realizado pela FUNDREM, em 1979, não se descuida desses aspectos, alertando para os impactos negativos que determinados empreendimentos poderiam ter para o ecossistema local, fragilizando-o, se não destruindo-o por completo.

Entre os empreendimentos que poderiam ter aspectos negativos para a restinga, o plano diretor cita a estrada litorânea Niterói - Rio das Ostras, então nos planos do DER, que fora objeto de estudo encomendado ao escritório do arquiteto $M$. Roberto. Este profissional alertava para o perigo que se constituía no loteamento de toda a restinga, como vinha ocorrendo, considerando que estes loteamentos, associados à implantação de uma rodovia de grande tráfego, não proporcionariam uma adequada preservação dos aspectos naturais da região. 


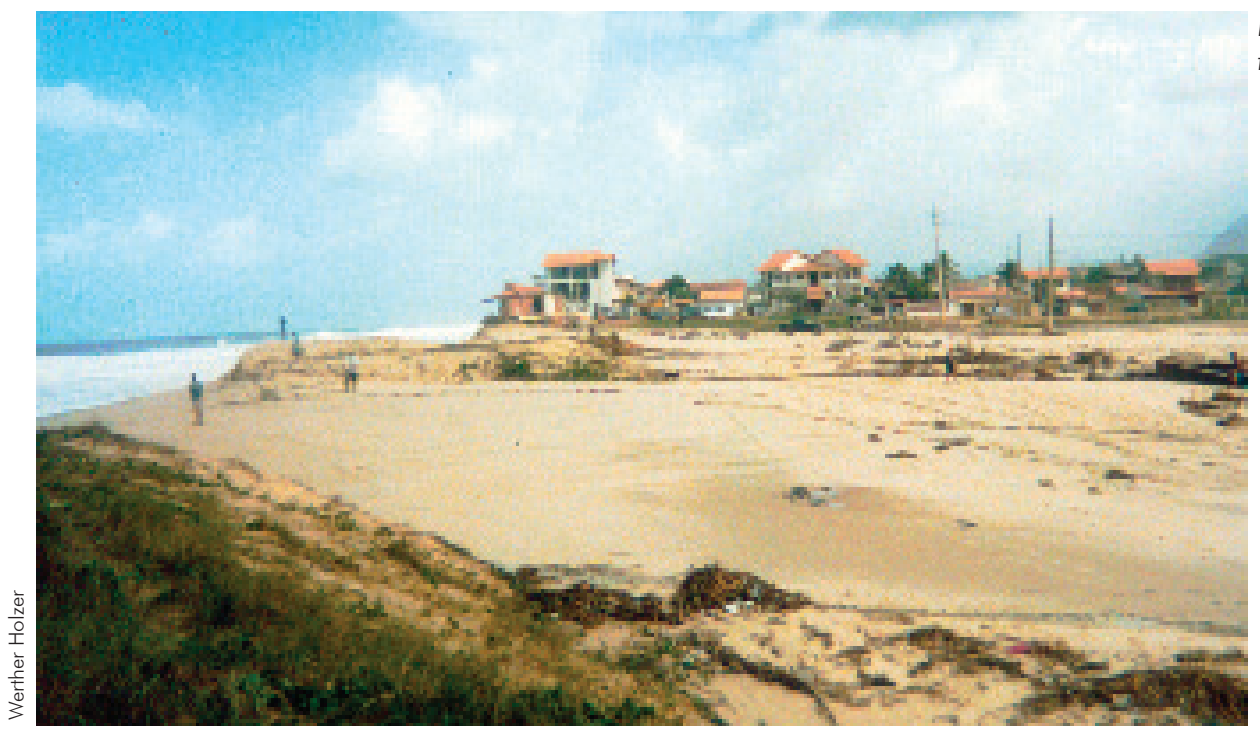

Dos objetivos que orientavam o plano diretor, deve ser destacado o da preservação de áreas com valor paisagístico, com especial destaque à restinga e às suas praias. Para atingir esses objetivos o plano diretor propunha coibir a ocupação das dunas e praias da restinga, de modo a manter a vegetação existente e as características especiais da área; além de obstar a construção de outras estradas ao longo da restinga, restringindo a circulação à via existente.

Segundo o plano diretor, a "Zona Especial da Restinga" deveria ser objeto de um plano urbanístico detalhado, que lamentavelmente não foi implantado. Dentre as proposições do plano diretor para que fossem atingidos os objetivos propostos, estava a de número 9, que determinava o estabelecimento "... de condicionantes ambientais para a ocupação das orlas marítima e lacustre, de modo a orientar a urbanização destas áreas".

Implementado o plano diretor, aprovado em dezembro de 1983, algumas medidas iniciais de salvaguarda à restinga e à orla marítima foram adotadas. Está determinado que na orla marítima deve ser respeitada faixa estabelecida pela regulamentação urbanística, além das disposições existentes no Código Florestal e demais legislações aplicáveis; que: "será considerada como ZNAM (Zona Non-Aedificandi Marítima) a faixa de 50 metros ao longo do mar a partir da linha média da maré."; que "os projetos de urbanização na área da restinga deverão respeitar a vegetação nativa e as dunas cujas características de excepcional beleza e raridade evidenciam a necessidade de sua preservação".

Podemos ver que tanto o plano diretor quanto o PDU consideravam a fragilidade do ecossistema da restinga e ofereciam mecanismos para sua preservação. No entanto, nesta ZNAM, por exemplo, foram implantados quiosques, e inclu- 


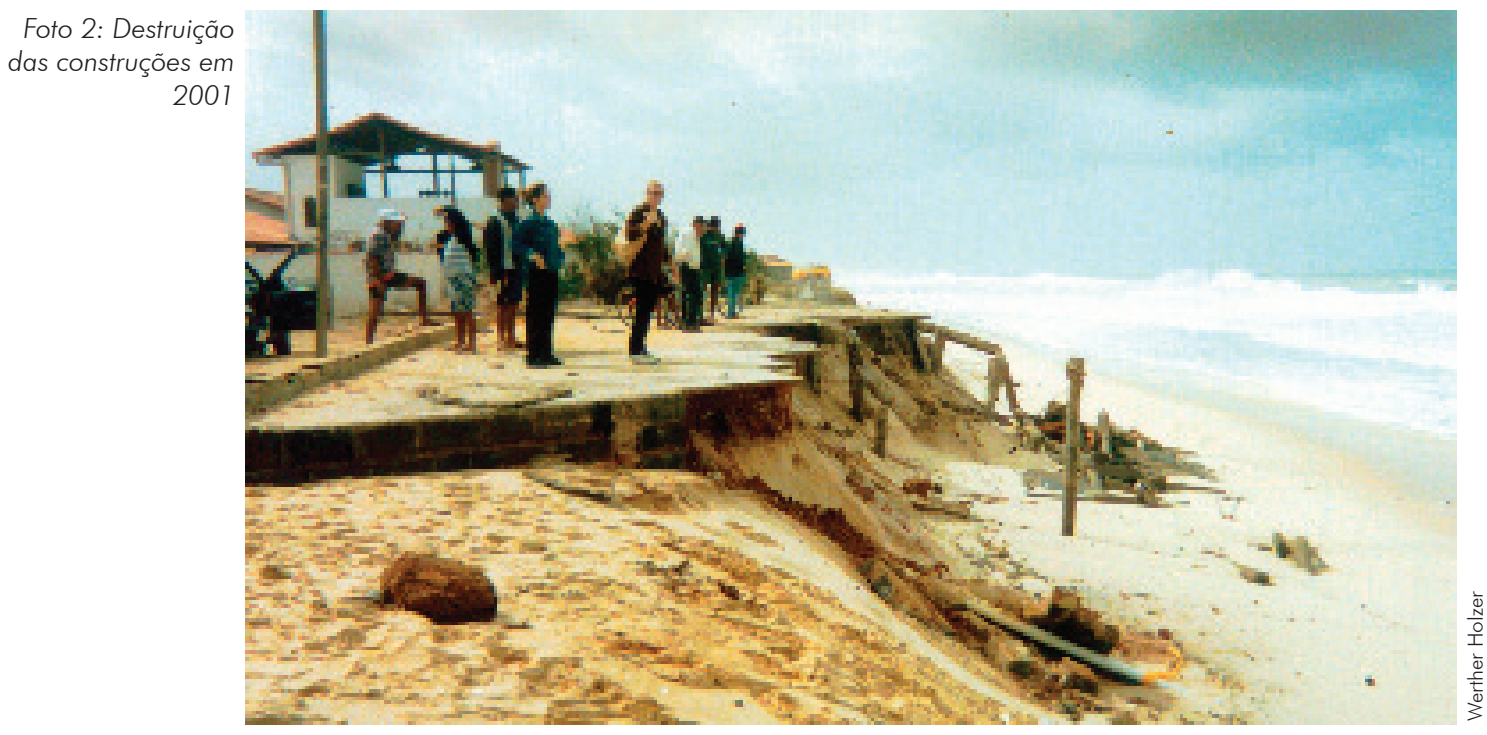

sive residências, destruídos por um ciclone em maio de 2001. Os quiosques foram implantados sobre a primeira faixa de vegetação de restinga, a que fixa o solo arenoso e o protege no embate com as marés, sobre uma rua projetada, ainda que inviável de ser implantada, configurada como área non aedificandi. Eis o motivo de sua destruição.

\section{Avaliação Preliminar dos Impactos da Urbanização Sobre a Vegetação}

Como foi exposto acima, a destruição das formações vegetais da restinga de Maricá tem levado à rarefação das espécies nativas, que atualmente só podem ser encontradas em manchas isoladas ou na APA.

A fisionomia da componente vegetal da restinga, compreendendo espécies nativas, revela ainda um potencial residual, que se encontra ameaçado de destruição, representado em grande parte pelas espécies de valor ornamental, com vista à preservação ambiental e à utilização no planejamento paisagístico de áreas litorâneas.

De modo geral, os estudos botânicos e paisagísticos carecem de um levantamento do potencial da vegetação da restinga de Maricá em termos de usos aplicados em tratamento paisagístico de áreas urbanas.

No que concerne ao potencial paisagístico da restinga de Maricá, no contexto da fisionomia da paisagem natural litorânea, a vegetação se apresenta como uma sucessão de "mosaicos" variados, formados de "jardins naturais", resultantes de um processo ecológico de fixação e distribuição de diversas espécies nativas. 


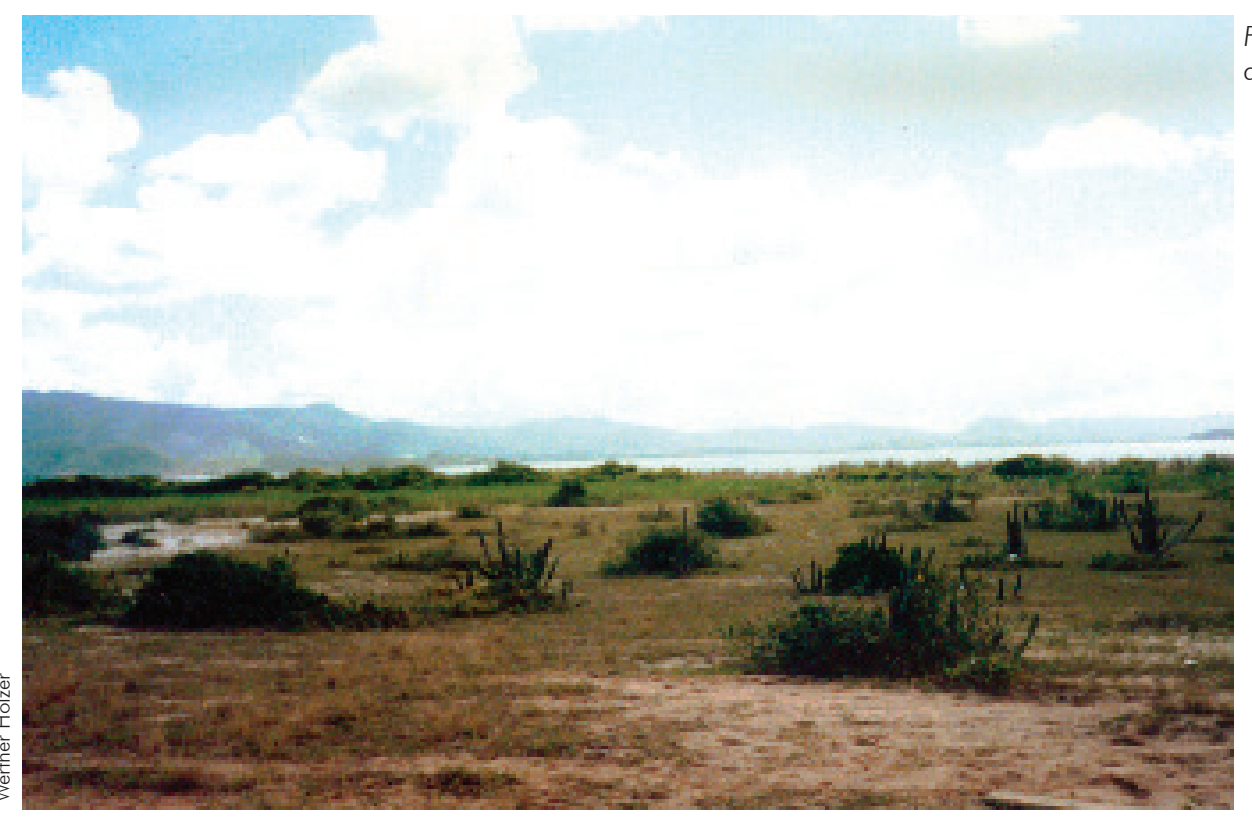

Foto 3: Restinga de Maricá

A organização desses diversos "mosaicos" de cunho ecológico e paisagístico determina, de certo modo, a composição de diferentes tipologias de jardins, nas quais são encontradas de muitas a poucas espécies reunidas, por meio de um processo de associação biológica ambiente/fauna/flora.

A presença de um determinado elemento vegetal (espécie), em torno do qual se associam e reúnem-se outras espécies, que mantêm graus de dependência ou não, torna possível esse estabelecimento interativo com o ambiente local em razão de diversos fatores, tais como: suporte, solo, ventilação, insolação, biomassa vegetal, concorrência espacial, etc.

Na formação inicial desses "jardins naturais", observa-se que há sempre um elemento vegetal colonizador, capaz de interferir no futuro desenvolvimento desses "jardins", existindo como componente vegetal dominante ou cedendo lugar ao estabelecimento de outras espécies em uma escala de desenvolvimento e de sucessão natural.

Para que se considere o potencial paisagístico de uma espécie, deve-se levar em conta as funções e características que ela desempenha na paisagem natural, nas diferentes zonas ou faixas do cordão arenoso da restinga: anteduna, duna, pós-duna, depressões e terrenos mais elevados.

No processo de formação dos "jardins naturais" da APA de Maricá, essas 58 funções e características são importantes para a fisionomia dos conjuntos vegetacionais, de modo a cada elemento contribuir para a visualização do todo e das partes, realçando os atributos paisagísticos em termos de forma, cor, textura, ritmo, volumetria, interação ecológica, entre outros. 
A partir da análise da fisionomia dos conjuntos vegetacionais, podem ser percebidos cinco níveis, ou extratos, na composição dos "jardins naturais": 1 - o revestimento do material arenoso em aclive suave e em áreas planas; 2 - o revestimento de material orgânico e argilo-siltoso, abrangendo o extrato vegetal de gramíneas e herbáceas; 3 - o revestimento vegetal do extrato arbustivo baixo; 4 - o revestimento vegetal do extrato arbustivo alto, trepadeiras e epífitas; 5 - o revestimento arbóreo, estabelecendo massa de vegetação compacta.

Em função desses níveis ou extratos formadores dos conjuntos vegetacionais, foram identificadas cinco tipologias de "jardins naturais", a saber:

Tipologia de revestimento - apresenta vegetação de porte rasteiro, formado pelo solo arenoso e de gramíneas ou porte relvado, sujeita à ação da salinidade, vento e insolação, e dependendo da localização, sujeita ao efeito das marés altas. Coloniza os primeiros metros de substrato, raramente observada fora da área de influência das marés. A partir dos 25 metros para o interior da restinga ocorrem outras espécies.

Tipologia de porte herbáceo - apresenta vegetação formada por espécies pioneiras (bromélias, gramíneas e cactos) que possibilitam fixar nutrientes e meio propício ao desenvolvimento de outras espécies no solo arenoso das antedunas, constituindo os primeiros arranjos vegetacionais.

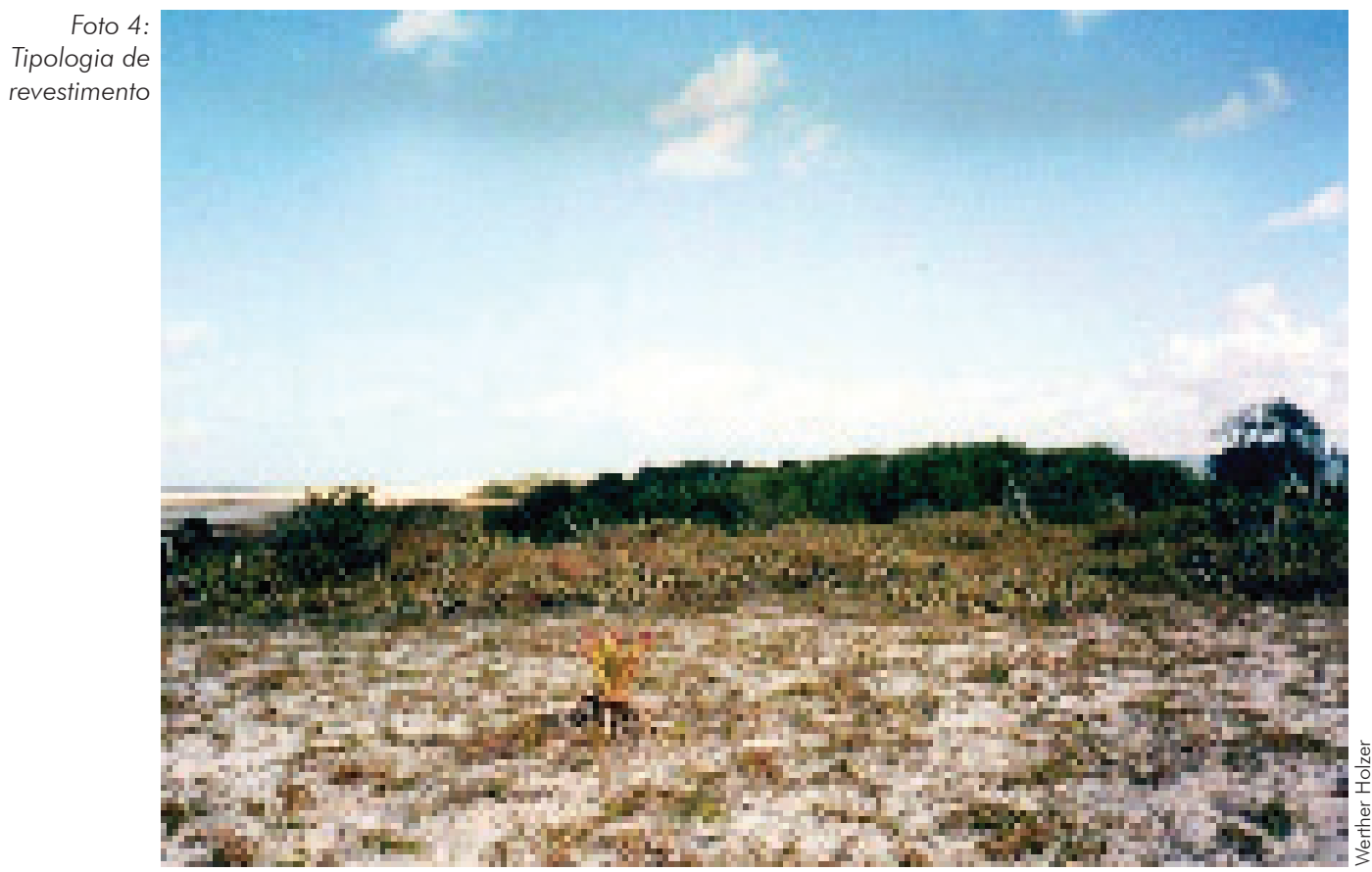


Tipologia de porte herbáceo e arbustivo - apresenta vegetação formada por espécies de herbáceas da faixa anterior e arbustos baixos, com ramos rentes ao solo após o cordão de dunas, possuindo altura variável de 1 a 3 metros.

Foto 5: Tipologia de porte herbáceo

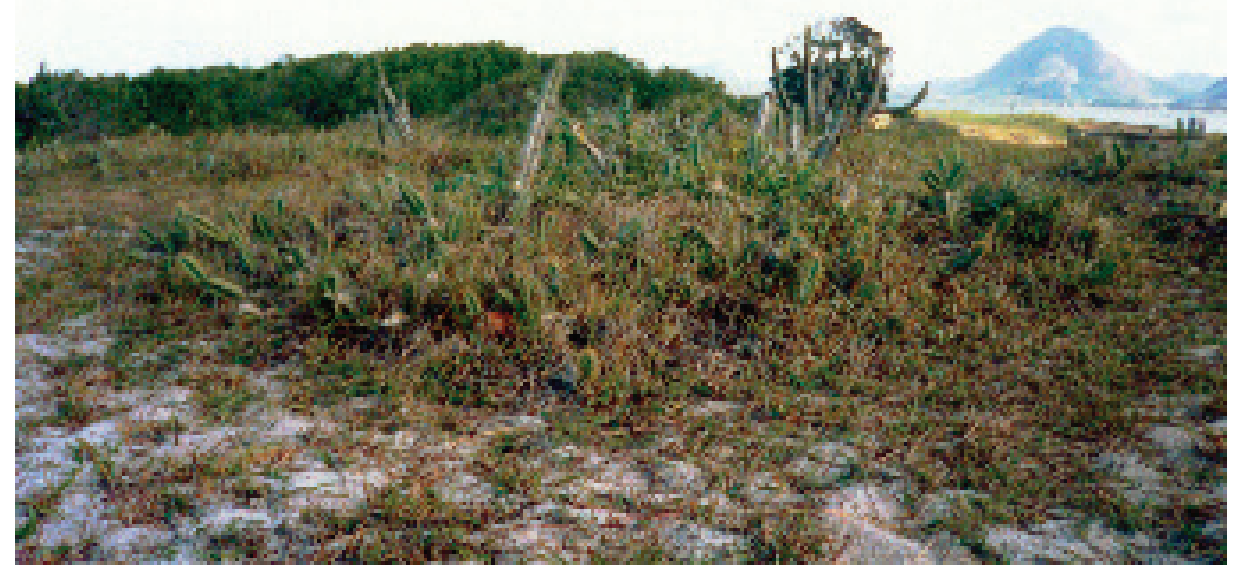

Tipologia de porte arbustivo/trepadeiras - apresenta vegetação caracterizada por grandes espaços livres de revestimento arenoso, alternados com aglomerados de manchas de vegetação - "jardins naturais" (herbáceas, arbustos, trepadeiras e epífitas). Nessas formações de 3 a 6 metros de diâmetro variável, em algumas áreas que apresentam depressões próximas ao lençol freático, ocorrem espécies higrófilas reunidas em pequenos bolsões e alagados, além de outras importantes espécies.

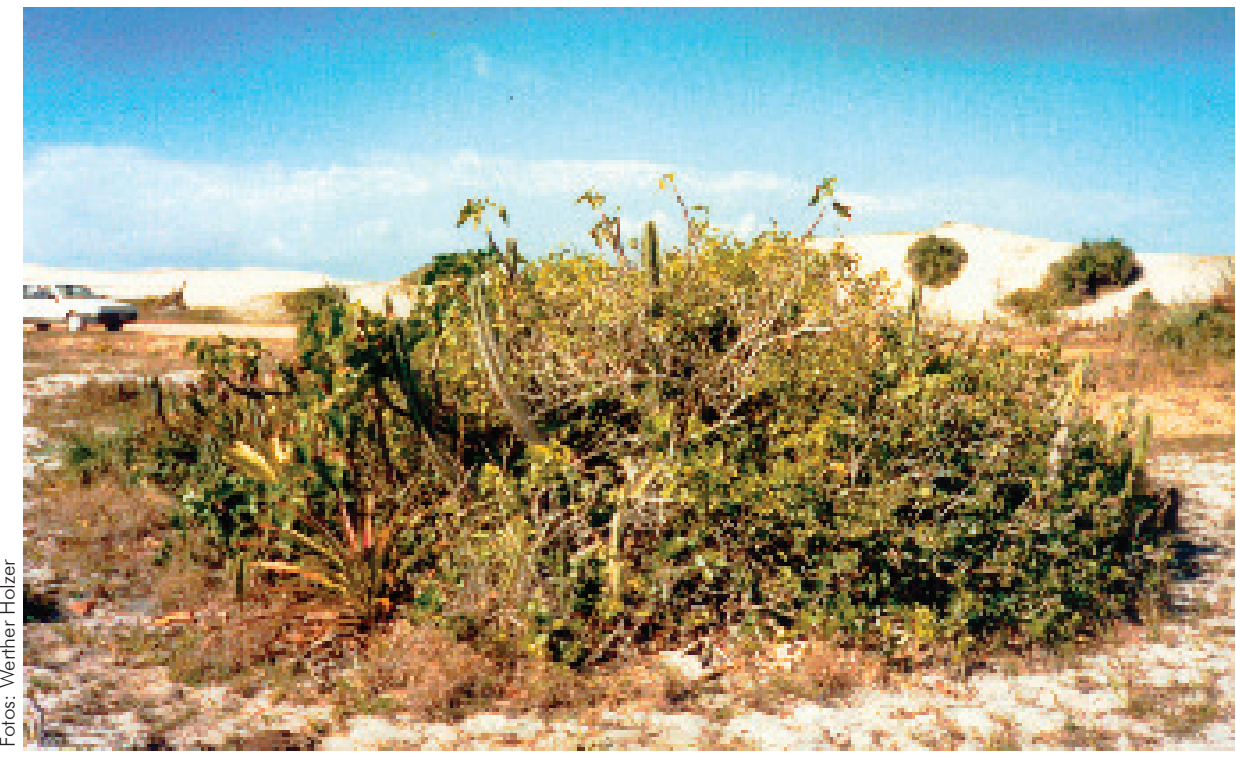

Foto 6: Tipologia de porte herbáceo/arbustivo 
Tipologia de porte arbóreo - apresenta vegetação predominantemente arbórea de 6 a 10 metros, que ocorrem em terreno mais elevado que os anteriores (mata de restinga).

Foto 7: Tipologia de porte arbustivo/ Trepadeiras

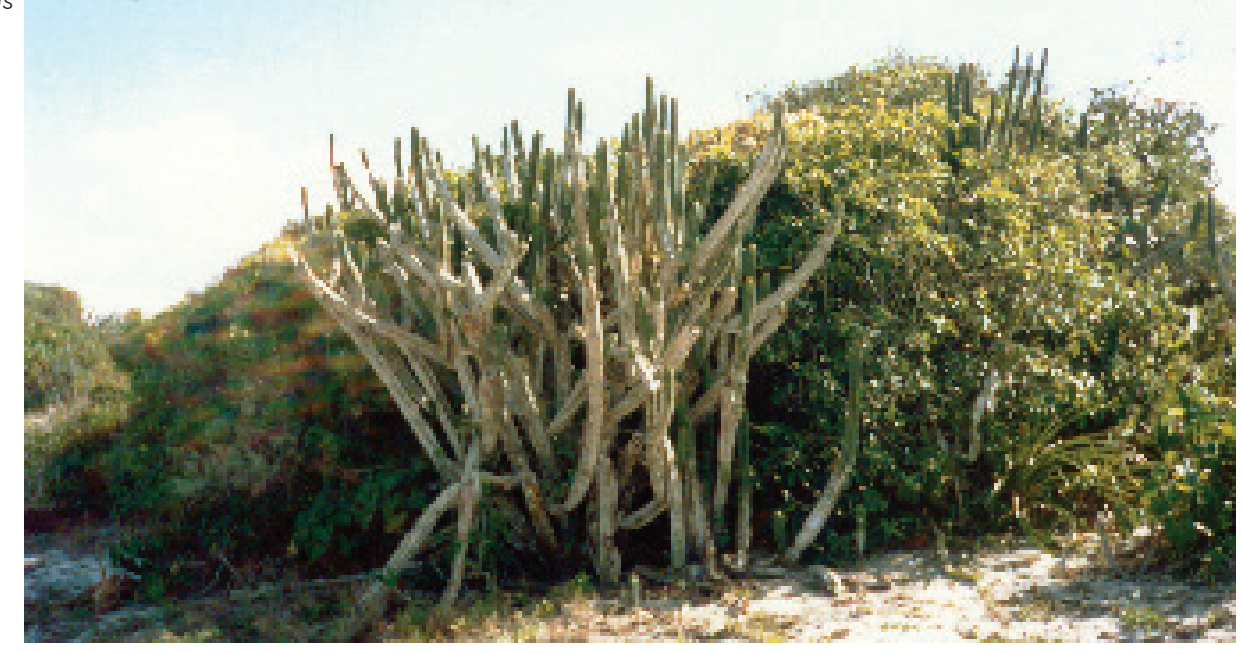

Foto 8: Tipologia de porte arbóreo

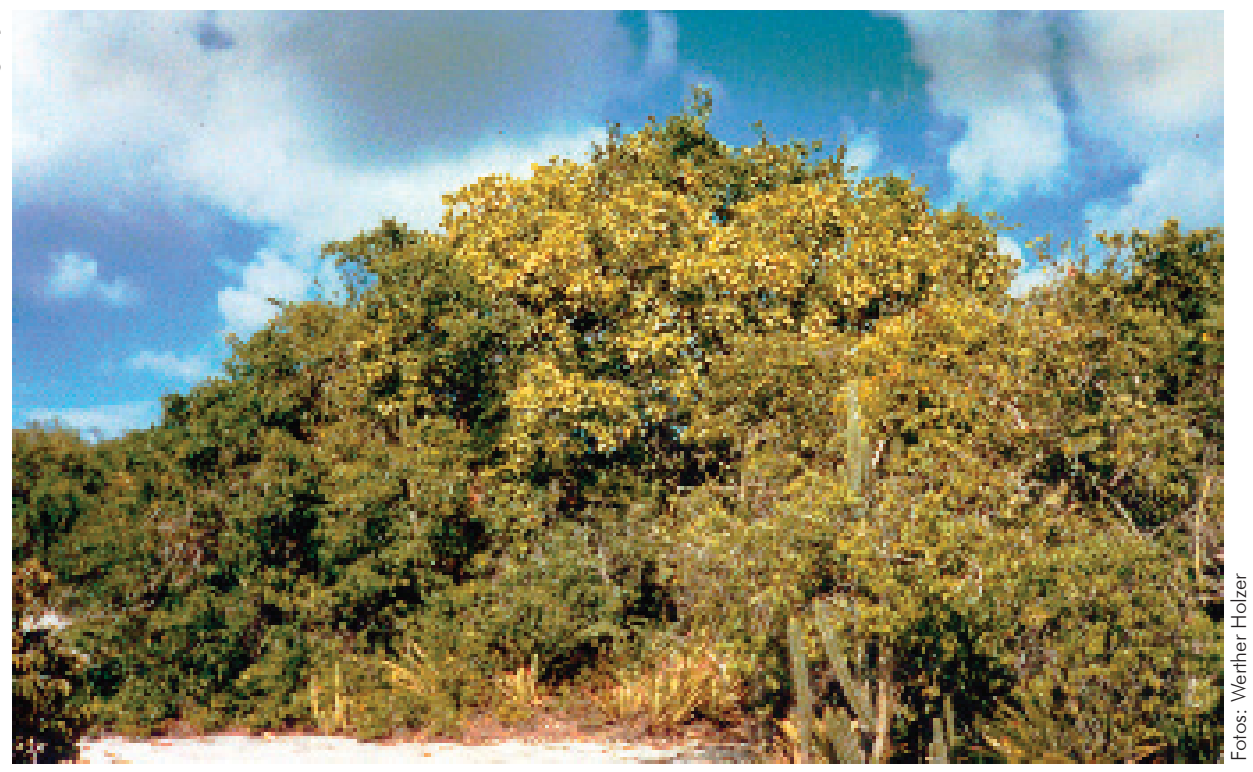

Como forma de intervenção humana, a urbanização é aquela cujos efeitos são mais deletérios, pois age diretamente na eliminação do ecossistema e não somente em sua degradação. Na ocupação da faixa litorânea por loteamentos, uma prática rotineira é a eliminação total da vegetação nativa para sua delimitação e urbanização, processo que se completa quando as unidades são implantadas. Quando há um ajardinamento do local, geralmente é feito com plantas exóticas. 
A eliminação de um ecossistema é acompanhada do empobrecimento da biodiversidade, com a possível extinção das espécies. No caso das restingas, pode haver a diminuição do próprio valor econômico do empreendimento imobiliário, pois a ausência de vegetação causa desestabilização do solo (essencialmente arenoso), provocando bloqueio de estradas, invasão das habitações por areia, além de assoreamento e obstrução de lagoas e cursos d'água - processo que pode ser observado em toda sua magnitude em ltaúnas - ES. Também as construções à beira-mar ficam diretamente expostas ao vento e à maresia, e em alguns casos à ação direta das marés. A cobertura vegetal, por outro lado, contribui para manter a permeabilidade do solo, que permite a alimentação dos lençóis freáticos, garantindo a estabilidade em seu nível e, conseqüentemente, o fornecimento de água potável na região.

Desse modo, a questão fundamental se relaciona com o planejamento do parcelamento das restingas, e a gestão ambiental da ocupação humana. Essa gestão exige uma reformulação nos modelos de parcelamento, na qual a APO pode ser um subsídio de projeto poderoso. No caso da restinga, a análise dos diferentes níveis de degradação da vegetação pode ser um indicador preciso de como se percebe e manejam-se os recursos naturais disponíveis, indicando que as opções atuais de traçado viário e de formato dos lotes e quadras impedem a efetiva preservação dos recursos, alterando os níveis de tolerância socioambiental das comunidades locais.

\section{Conclusão}

Diante do quadro de degradação da paisagem litorânea, dos impactos socioambientais desencadeados pela intensa urbanização pouco ou nada planejada, os ecossistemas litorâneos, como outros, vêm sendo destruídos e substituídos por outros indicadores ambientais. Dentre estes, a vegetação constitui elemento fundamental na aferição e avaliação dos efeitos da ocupação urbana, e até como marcador da apropriação econômica, social e ambiental que se faz da paisagem. Desvelados os entrelaçamentos, no âmbito da preservação e do planejamento ambiental, e a lógica dos interesses econômicos determinantes das ações dos proprietários de terra e dos incorporadores imobiliários e da inércia das políticas públicas (ante a amplitude da legislação ambiental), é possível pensar que todos esses fatores são determinantes na reconfiguração das paisagens que compõem a área de proteção ambiental, objeto de nosso estudo.

processo de urbanização clássico, principalmente destinado a abrigar complexos turísticos, industriais e habitacionais, tem causado grandes devastações nas áreas de restinga. Mesmo que parte de suas áreas sejam mantidas intactas, as áreas devastadas (devido ao nosso conhecimento ainda incompleto 
da amplitude das interações ambientais e à fartura de espécies endêmicas) perdem muito de sua riqueza biológica e de seu equilíbrio ambiental e, portanto, seu potencial produtivo.

As restingas, enquanto ecossistema típico da zona costeira, encontram-se totalmente contidas em terras continentais, possuindo grande importância para a estabilidade do meio marinho. A vegetação existente é própria e tem papel fundamental na fixação dos substratos (dunas móveis de areias) em relação a tempestades e ventos, ainda mais nestes tempos de aquecimento global, sobre o qual se tem pouca informação precisa, mas que pode ter um impacto enorme em toda a área costeira. A vegetação possibilita a subsistência de uma diversidade de espécies animais que têm nas matas das dunas um hábitat específico (CLARK, 1985). Sua eliminação aumenta a velocidade de expansão das dunas (COUTINHO, s.d.), criando problemas ambientais imediatos ao seu entorno, com a ocupação e o soterramento de áreas significativas pelas areias impulsionadas pelos ventos (RIO GRANDE DO NORTE, 1989), trazendo conseqüências no custo de equipamentos para sua remoção, além de problemas de segurança nas estradas e na consolidação de áreas habitacionais.

As dunas possuem um alto valor para as comunidades, tanto por seu caráter paisagístico como ambiental, devido às excepcionais qualidades cênicas, biológicas e edafológicas. Entretanto, mostram-se especialmente sensíveis a qualquer forma de assentamento humano que desestabilize sua estrutura por completo. Esta desestabilização ocorre quando da retirada de vegetação e areia, além da filtragem de seus aqüíferos.

De modo geral, nas restingas, justamente pelo fato de ocorrerem sobre terrenos planos do litoral, acontecem as maiores explorações, pelas mais diversas formas de assentamento humano, com destaque para a urbanização desordenada. Esses fatos justificam um cuidado especial do ponto de vista paisagístico e socioambiental em termos morfológicos, estéticos, culturais e econômicos, sendo considerados os remanescentes de vegetação como simples "mato" por todos que nela constroem.

Sua vegetação não possui o porte nem é o "totem cultural" em que se converteu a mata atlântica. Paradoxalmente, a erradicação intensiva da vegetação de restinga a transforma em ambiente raro, isto é, excepcional. Tal situação torna, de imediato, esses ecossistemas paisagisticamente interessantes (como já o são em termos ambientais), na medida em que abrigam formas especiais de associação entre flora e fauna de ecossistemas diversos.

Diante desse quadro, a vegetação, como possível marcador referencial no processo de preservação ou de degradação paisagística, aponta para a questão de parâmetros comparativos de pós-ocupação da urbanização no estudo de 
áreas de restinga. Nesse sentido, cabem algumas questões que conduzem a um conjunto de reflexões, as quais podem ser chamadas de temáticas:

- Frente ao processo de expansão urbana e a necessidade de um planejamento socioambiental da paisagem litorânea, qual é o papel das áreas de proteção ambiental de restinga em termos da preservação e manejo de sua vegetação?

- Quais os segmentos significativos que podem ser inseridos nos modelos de planejamento paisagístico ambiental, destinados à preservação permanente, de modo que a população tenha assegurada a efetiva implementação de um gerenciamento costeiro dos recursos naturais?

- De que forma seriam privilegiados pelo planejamento urbano os loteamentos e assentamentos humanos que conservassem partes significativas de vegetação de restinga, de modo contínuo e sucessivo, vinculando-as à implementação de projetos de desenvolvimento auto-sustentáveis?

- Quais as novas concepções e padrões de parcelamento do solo urbano, geradas no contexto de um planejamento paisagístico-ambiental?

- De que modo a vegetação pode configurar-se como marcador de uma avaliação pós-ocupação na urbanização de restinga?

A proposta temática principal já aponta para possíveis desdobramentos deste trabalho, ampliando-o para um quadro urbano mais geral, a partir da avaliação dos conjuntos vegetacionais de restinga e medidas de conservação e planejamento que permitam estabelecer parâmetros de análise comparativa, orientando novos padrões de ocupação ordenada dos ecossistemas de restinga, relacionando-os com a gestão auto-sustentável da urbanização em áreas litorâneas.

Nesse sentido, a proposta de utilizar-se a vegetação de restinga como marcador na avaliação pós-ocupação, que é objeto do trabalho o qual vem sendo desenvolvido, ainda que a título de ensaio, já tem acumulado material bibliográfico e dados de campo sobre o tema. 


\section{Bibliografia}

Ab'SABER, Aziz N. Os domínios de natureza no Brasil: Potencialidades paisagísticas. São Paulo: Ateliê Editorial, 2003.

ANDRADE, M. A. B. A Baixada Santista: Aspectos geográficos. São Paulo: Edusp, 1967.

BLOUIN, M.; CONNOR, E. S. Is there a best shape for nature reserve?. Biol. Conserv., n. 32, p. 277-288, 1985.

CLARK, J. R. Coastal Ecosystems Management: A Technical Manual for the Conservation of Coastal Tones Resources. Nova York: John Wiley, 1977.

COUTINHO, Leopoldo Magno. Mata costeira, restinga e mangue. São Paulo: ABAP, s.d. (apostila)

CRICHYNO, Jorge; HOLZER, Werther. Área de proteção ambiental: Potencial paisagístico-ambiental da vegetação aplicada ao paisagismo. In: V ENCONTRO NACIONAL DE ENSINO DE PAISAGISMO EM ESCOLAS DE ARQUITETURA E URBANISMO NO BRASIL. 2000, São Paulo. Anais... São Paulo: Semiotic Systems, 2000, CD-ROM.

CRICHYNO, Jorge. Uso potencial da vegetação de restinga (Maricá - RJ): critério para seleção de espécies em projetos de paisagismo. In: II ENCONTRO NACIONAL DE ENSINO DE PAISAGISMO EM ESCOLAS DE ARQUITETURA E URBANISMO NO BRASIL. São Paulo, UNIMARCO, 1996. p. 131-144.

DEAN, Warren. A ferro e a fogo: A história e a devastação da mata atlântica brasileira. São Paulo: Companhia das Letras, 1996.

GOLDSTEIN, E. L. Exploration in birdland geometry. Urban Ecology, n. 5, p. $113-$ $124,1981$.

HOLZER, Werther. Diagnóstico e propostas de projeto urbano e paisagístico para a área de Proteção Ambiental de Maricá - RJ. Projeto de Pesquisa. Niterói: UFF/ PROPP/TUR, 1999.

LAMEGO, Alberto. O homem e a restinga. 2 ed. Rio de Janeiro: Ed. Lidador, 1974.

RIO GRANDE DO NORTE (ESTADO). Secretaria de Planejamento/IDEC. Plano de Manejo do Parque das Dunas de Natal. Natal: IDEC, 1989.

SEMAM/IEF. Reserva da biosfera da Mata Atlântica. Rio de Janeiro: SEMAM/IEF, 1994. 